\title{
The social psychology of seismic hazard adjustment: re-evaluating the international literature
}

\author{
C. Solberg ${ }^{1}$, T. Rossetto ${ }^{2}$, and H. Joffe ${ }^{1}$ \\ ${ }^{1}$ Division of Psychology and Language Sciences, University College London, Gower Street, London, WC1E 6BT, UK \\ ${ }^{2}$ Department of Civil, Environmental and Geomatic Engineering, University College London, Gower Street, \\ London, WC1E 6BT, UK
}

Received: 25 November 2009 - Revised: 18 June 2010 - Accepted: 4 July 2010 - Published: 3 August 2010

\begin{abstract}
The majority of people at risk from earthquakes do little or nothing to reduce their vulnerability. Over the past 40 years social scientists have tried to predict and explain levels of seismic hazard adjustment using models from behavioural sciences such as psychology. The present paper is the first to synthesise the major findings from the international literature on psychological correlates and causes of seismic adjustment at the level of the individual and the household. It starts by reviewing research on seismic risk perception. Next, it looks at norms and normative beliefs, focusing particularly on issues of earthquake protection responsibility and trust between risk stakeholders. It then considers research on attitudes towards seismic adjustment attributes, specifically beliefs about efficacy, control and fate. It concludes that an updated model of seismic adjustment must give the issues of norms, trust, power and identity a more prominent role. These have been only sparsely represented in the social psychological literature to date.
\end{abstract}

\section{Introduction}

Earthquake disaster research takes for granted that "earthquakes do not kill people, buildings do". Buildings are built and inhabited by people who make a range of choices that shape whether these buildings cause earthquake-related deaths. This paper reviews the social psychological factors that shape human adjustments to seismic risk. These include individual feelings and thought processes; the socialpsychological effects of gender, race and class; and cultural norms, values and beliefs. The research reviewed strongly suggests that psychological, societal and cultural factors shape seismic adjustment.

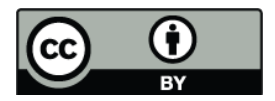

Correspondence to: H. Joffe (h.joffe@ucl.ac.uk)
Over the past 40 years behavioural sciences such as psychology have attempted to predict and explain levels of seismic hazard adjustment. Psychological research explains seismic adjustment via models that include risk perception, norms, attitudes and intentions as key variables. This paper addresses the causal processes common to these psychological models. It starts with clarifying what seismic adjustment means, how it is measured and its global prevalence. It proceeds to review research on seismic risk perception. Following this it looks at norms and normative beliefs, focusing particularly on the issue of trust between risk stakeholders and earthquake protection responsibility. It then considers research on attitudes towards seismic adjustment attributes, specifically beliefs about individual and collective control, self-efficacy and fate. The penultimate section critiques social-psychological models of seismic adjustment from a wider theoretical perspective and suggests extensions to the dominant models. The paper concludes that an updated model of seismic adjustment must give a more prominent role to cultural and normative influences and to trust.

\section{Defining and measuring seismic hazard adjustments}

This paper refers to the long-term protective behaviours undertaken by households and individuals in anticipation of an earthquake as seismic adjustment behaviours. For the purpose of this paper seismic adjustments are all types of actions and behaviours undertaken by individuals and households that have the capacity to either reduce immediate risk of damage and loss during an earthquake, or to prepare for postimpact conditions that might adversely affect survival probabilities (Mulilis and Lippa, 1990; Spittal et al., 2006; Tierney et al., 2001; Turner et al., 1986). Examples of actions that reduce risk include seismic retrofitting and securing the contents of houses, while examples of post-impact preparations

Published by Copernicus Publications on behalf of the European Geosciences Union. 
are ensuring supplies of food, water and medicine, having insurance and planning for the reunion of one's family. It must be noted that the term adaptation, in broad usage in the wider literature on hazards and disasters, does not correspond directly with the term adjustment. Adaptation is defined as collective, long-term changes made in response to hazards emerging from changing ecological and social conditions, while adjustments refer more narrowly to coping mechanisms developed to mitigate and respond to specific hazards (Clarke Guarnizo, 1992). This paper will consistently refer to adjustments in keeping with the psychological literature it reviews.

Seismic adjustment is typically measured by surveys in which a sample of participants indicates which of a predetermined list of actions they have undertaken. Levels of adjustment are then found by summing up the "yes" responses, and a ratio computed to derive how close participants are to optimal adjustment levels. As Kirschenbaum (2004, 2005) has persuasively argued, hazard adjustment is not a simple one-dimensional entity, but should be divided into separate constructs that may have distinct sets of predictors (see also Lindell et al., 2009; Mulilis, 1999; Russell et al., 1995). Kirschenbaum (2004) derived four factors that explained a significant proportion of the variance in his data: levels of essential provisions stocked in the household; knowledge of and ability to use survival skills; having household emergency plans; and the presence of structural mitigation measures (e.g., seismic retrofitting or aseismic construction). Such multi-factorial models represent an advance on unidimensional models. However, measures that prove useful for one place are likely to give artificially low or high adjustment estimates when applied to a different location. For example, the set of possible and effective seismic adjustments for a household living in slum conditions in Mexico City would be substantially different to the opportunities available to an upper-class household residing in a highly developed urban area. Thus there is a tension between generalisability on the one hand, and sensitivity to local hazard contexts and adjustment opportunities on the other.

What do people do to protect themselves from seismic hazards? The West Coast of the USA has been surveyed repeatedly to ascertain levels of seismic adjustment. Here adjustments related to enhancing post-impact response and recovery are by far the most widespread. Findings indicate that adoption and implementation has gone up over time, but not consistently. Earthquake insurance, in particular, had increased from approximately 5\% in 1973 to approximately 50\% in 1993 among at-risk Californian homeowners (Palm, 1995). Yet this trend has since reversed, with only approximately $12 \%$ of Californian households having earthquake coverage in 2007 (Insurance Information Institute, 2008), possibly due to increased costs to households after the partial failure and subsequent restructuring of the earthquake insurance markets following the 1994 Northridge earthquake (Comerio, 2004). Some of the post-impact adjustments (e.g., stockpiling of food and water) have utility for more than one hazard, which might explain their greater relative adoption rate.

Pre-disaster, earthquake-specific preparedness and mitigation (e.g., structural retrofitting) adoption rates are consistently much lower, and have not increased significantly from the early 1970s to the present time in the US (Jackson and Mukerjee, 1974; Nguyen et al., 2006; Russell et al., 1995; Turner et al., 1986). Farley's (1998) report on changes in seismic adjustment levels in the US New Madrid Seismic Zone after a widely publicised, but ultimately unfounded earthquake prediction in 1990 shows a similar pattern: response and recovery-related seismic adjustments were more widespread than preparedness and mitigation adjustments were, albeit with higher rates of adjustment compared to the Western US.

The majority of the research in this field is North American and the only longitudinal studies are based on North American samples. However, research from other parts of the world including Iran, Turkey, Israel, Japan, Morocco, Romania and New Zealand tends toward the same overall conclusion as the US-based research: In sum, a large proportion of respondents do nothing or very little to adjust to seismic hazards, and when they do take action, it is significantly more likely to be response and recovery-related than mitigative (Asgary and Willis, 1997; Kasapoglu and Ecevit, 2004b; Kirschenbaum, 2005; Palm, 1998; Paradise, 2006; Spittal et al., 2008).

\section{Seismic risk perception}

Seismic risk reduction efforts have often operated on the assumption that communicating scientific estimates of seismic hazard and societal vulnerability to exposed communities will raise risk perceptions and concerns to levels that will drive seismic adjustments (Smith, 2006). In order to gauge the validity of this strategy, researchers have examined correlations between levels of risk perception and seismic adjustments. Findings from such studies are evaluated in the following sections and grouped under the three main categories of psychological, social and material influences on seismic risk perception. The link between people's seismic risk perception and their uptake of seismic adjustments is then explored.

\subsection{Psychological factors shaping seismic risk perception}

Seismic risk perceptions have been conceptualised in a variety of ways, broadly encompassing social, cognitive and emotional dimensions (e.g., Lindell and Perry, 2000; Mulilis, 1995; Palm and Carroll, 1998). Seismic risk perception is generally measured in terms of various kinds of subjective distances between hazards and targets. One is social distance: is the threat directed at oneself, ones loved ones, at the 
average other person, or at total strangers? Another is temporal: will an earthquake happen sooner or later? A further dimension is based on probability: is an earthquake likely or unlikely? Yet another is spatial: will an earthquake occur where one is or elsewhere? There is also a dimension that addresses consequence: will the damage be small or great? A further dimension pertains to control: is seismic risk within your sphere of control or does it exceed your capacities? Finally seismic risk perception can be measured in terms of emotional distance: does the threat of earthquakes evoke strong or weak emotional responses?

Despite the vast literature, there is no agreement on which of these risk perception measures best predicts the response to seismic hazards. Therefore, approaching the issue from a different perspective other researchers have argued for more content-based conceptions of risk, examining how risks are constructed by people within certain social and cultural frameworks (e.g., Douglas and Wildavsky, 1983; Joffe, 1999, 2003). Of late, the two approaches have been merged in "cultural cognition" theory (e.g., Kahan et al., 2007), which has close affinities with system justification theory (Jost et al., 2004). Cultural cognition theory states that individuals are disposed to selectively credit or dismiss risk claims in ways that are congruent with their preferred views on how culture and society should be organised (Kahan et al., 2007). These worldviews are generally organised along two axes: hierarchy versus egalitarianism, and individualism versus collectivism. System justification theory shows that the cause of this dispositional tendency is that most individuals and groups are fundamentally motivated to believe that the world as they perceive it is just, legitimate and beneficial (Jost et al., 2004). As suggested in the introduction, earthquake vulnerability is literally constructed in the course of the development of the social and built environment. Given the assumptions of cultural cognition and system justification theory, it follows that the people who benefit the most from these developments will be more disposed to bolster their preferred worldviews. This also means that these same people will be the ones who are least likely to see earthquakes as significant risks. This raises the questions: how do people understand earthquake risk and how does their past experience of events influence their risk perception? These are addressed in the following sections.

\subsection{Earthquake experience and seismic risk perception}

A number of psychological variables have been consistently linked to increased perception of risk. First and foremost, past experience of damaging earthquakes has been found to increase risk concerns (Dooley et al., 1992; GruevVintila and Rouquette, 2007; Karanci and Aksit, 1999; Kasapoglu and Ecevit, 2004a; Jackson, 1981; Lindell and Prater, 2000; Palm, 1998; Plapp and Werner, 2006; Rüstemli and Karanci, 1999). However, the strength of the relationship between past experience and increased concern seems to vary depending on how earthquake experience is measured (Lindell and Perry, 2000), and on the outcome of the experience (i.e., personal loss or not) as covered in Sect. 3.1.2 below (Helweg-Larsen, 1999; Mileti and O'Brien, 1992). Thus experience certainly plays a role in the salience of earthquakes in the lives of those affected by them but its impact is variable (Lindell and Perry, 2000).

Earthquakes create opportunities for narrating stories about oneself and one's community. Their rehearsal and retelling on social occasions, for example, can be considered one cause of their impact on risk perceptions; rehearsal of the emotionally charged event strengthens its memorability and makes the earthquake a salient part of the person's life history (Er, 2003; Neisser, 1996). Studies have also found a positive correlation between the extent to which one thinks, talks and reads about earthquake hazards - so-called critical awareness (Paton et al., 2005) - and seismic risk perception (Farley, 1998; Gruev-Vintila and Rouquette, 2007; Lindell and Prater, 2000; Turner et al., 1986). Furthermore, earthquake stories can unite disaster victims, providing them with additional emotional attachments to their community, peer groups and even socially distant groups, through vivid memories of shared experiences. As earthquake experiences become part of a group's identity, seismic risk might become a recurrent motif in the biographies of group members (Bendix, 1990), thereby maintaining the salience of seismic risk.

Despite living in high earthquake risk communities, being aware of future risk and having memories of past earthquakes, people's critical awareness of earthquakes is often low in the absence of trusted warnings or predictions of imminent risk (Armas, 2006; Jackson, 1981; Turner et al., 1986). In short, a significant proportion of people in seismically active areas, who have had past experiences of earthquakes, do not manifest ongoing concern regarding their vulnerability to seismic hazards.

Several studies have reported that when people are specifically asked to compare earthquakes to a range of other hazards, earthquakes rank high among natural hazards, and relatively high in overall risk consciousness. In a North American study Flynn et al. (1997) reported that earthquakes ranked fifth of 15 hazards in a Portland, Oregon sample, highest of all natural hazards. Lai and Tao (2003) surveyed risk perceptions in Hong Kong and found a sharp divide between perceptions of threats to the local and global environment - earthquakes ranked second lowest of 20 environmental threats to the local environment, but fifth as a global threat. This may well be attributable to the historically low seismic activity in the Hong Kong area, coupled with awareness of massively destructive earthquakes in mainland China. Plapp and Werner (2006) surveyed residents of southern Germany, who experience small and medium-sized tremors on a regular basis. Of 16 hazards, earthquakes were ranked fourth, again highest of all natural hazards. Kohiyama and colleagues (Kohiyama et al., 2008) surveyed 3150 respondents 
across 7 Japanese cities shortly after the Mid-Niigata earthquake of 2004. They found that although $79 \%$ of respondents were concerned about an earthquake, more than $90 \%$ ranked earthquakes as a lesser concern than issues such as crime, fire, environmental hazards and household finances. In all locations regarded to have medium to high earthquake risk, it seems that although earthquakes are seen to represent a potent threat, other risks are generally prioritized. Having said this, it should be noted that risk ranking measures are inherently unstable. People's priorities change quickly in reaction to changing circumstances. As such, future researchers might conduct longitudinal studies of risk rankings in order to gauge their distribution and variability.

The research reviewed in this section suggests that while earthquake experience increases seismic risk salience, its effects on levels of concern are variable. This counter-intuitive finding demonstrates the importance of conducting carefully conceived empirical research.

\subsection{Psychological biases in seismic risk perception}

A major strand of risk perception research has dealt with how people quantitatively estimate uncertain risk when making decisions, and how these estimates and decisions differ from normative, expert opinion. Such differences are attributed to psychological processes that bias risk perceptions (e.g., Kahneman and Tversky, 1979). One such bias is the "optimistic bias" (OB) displayed in the face of being affected by a risk. $\mathrm{OB}$ is a pattern of judgments where people see themselves as being less likely to be harmed by future risks than peers of a similar age and gender who they are asked to compare themselves to (Helweg-Larsen, 1999; Spittal et al., 2005). A number of studies have found that people display an optimistic bias in relation to natural hazards. Jackson (1981) reported that a majority of respondents in the Pacific North West either believed they would not experience an earthquake or that if they did, it would not harm them. Furthermore, experiencing an earthquake without suffering losses or injuries led respondents in two US studies to report that they were more optimistic about future earthquake consequences relative to peers who had suffered injuries or losses (Helweg-Larsen, 1999; Mileti and O'Brien, 1992). Such studies speak not only to the issue of $\mathrm{OB}$ but to the impact of past experience on $\mathrm{OB}$, in this case experience of injury or loss diminished the relative OB. In general OB creates an illusion of safety that helps people to cope with the psychological stress related to risks.

Only three studies have examined the effects of $\mathrm{OB}$ on seismic risk perception directly. Burger and Palmer (1992) found that students who had experienced the 1989 Loma Prieta earthquake showed no OB directly after the event, but that $\mathrm{OB}$ returned to pre-earthquake levels 3 months after the event. In a similar study, Helweg-Larsen (1999) surveyed survivors of the 1994 Northridge earthquake. She found that immediately after the event, there was no OB for earthquakes. In contrast to Burger and Palmer's findings, she did not find a return to OB in the months after the event. Spittal et al. (2005) examined OB in Wellington, New Zealand residents in relation to three targets - self, an acquaintance and the 'average other' in Wellington, and on two risk perception criteria - likelihood of harm and likelihood of damage to property. Respondents judged that they were more likely to sustain damage to their own property than either an acquaintance or an average other. Thus fear of financial loss may not be susceptible to OB. However, as compared to an acquaintance, respondents thought they were less likely to suffer harm, which provides some indication of OB. Contrary to expectations, there was no difference between estimates of own harm and that of the average other. These studies indicate that $\mathrm{OB}$ is context-dependent and may differ according to whether personal harm or financial loss is being evaluated.

Palm and Carroll (1998) tested the hypothesis that OB in regards to earthquake risk is more prevalent in individualistic cultures, that is, those that emphasise feelings of optimism, high self-esteem and self-reliance. Their comparisons of Californians (who belong to an individualistic culture) and Japanese (belonging to a more interdependent, pessimistic, lower self-esteem culture) found that Japanese respondents displayed less $\mathrm{OB}$ in relation to seismic risks. Thus it can be argued that $\mathrm{OB}$, and possibly other risk biases, are constrained by cultural norms regarding how the self is constructed in a given society.

Celsi et al. (2005) found evidence of a more subtle bias in Californians' perceptions of earthquakes. Other than those directly affected by earthquakes, most people who experience earthquakes do so in a location where shaking has been attenuated due to distance from the epicentre and ground conditions. Thus they tend to underestimate the potential damage that could occur from an earthquake with a given, publicly reported magnitude. With repeated experience, this can create an earthquake risk attitude that is skewed towards underestimation of risk, contributing to optimistic bias and feelings of invulnerability.

Other biases have also been described in the literature. Mileti and O'Brien (1992) conclude that people who had not suffered losses in the 1989 Loma Prieta earthquake were less likely to heed aftershock warnings: "Those who experience little or no loss in the impact of a disaster may be prone to "normalization bias" when interpreting post-impact warnings for subsequent risk: "the first impact did not affect me negatively, therefore, subsequent impacts will also avoid me"." (p. 53).

Thus people often seem motivated to minimize concerns for their own danger, compared to that of others, regarding seismic risk. The literature suggests that this is partly related to culturally contingent notions of the self - in collectivistic cultures the emphasis on a relational, interdependent self-concept militates against such optimism. This suggests that optimism would be a less common psychological coping mechanism in more collectivist societies. 


\subsection{Social factors and seismic risk perception}

The "white male effect" is seen across a range of risk perception studies, including seismic risk. This is the observation that members of socially powerful groups (which in Western countries overwhelmingly are white males) see threats to self, community and society as less risky and more manageable than do members of non-dominant groups.

Both cultural cognition theory and system justification theory predict and explain this. They state that individuals living in relatively developed and stable societies are strongly motivated to believe that the status quo is just, legitimate and beneficial. It follows that potential threats to the status quo such as a major impending earthquake - are often denied, interpreted as manageable by the system, or seen as threatening mainly to outgroups (Feygina et al., 2010).

Cutter et al.'s (2003) overview of the hazard vulnerability literature finds that groups with less social, economic and psychological power, such as females, the old and the young, ethnic minorities, groups low in socioeconomic status (SES) and populations with special needs (e.g., physically or mentally challenged people, homeless, transients and tourists) are most vulnerable to environmental hazards. A reasonable prediction on the basis of these findings might be that the more vulnerable groups have correspondingly higher seismic risk perceptions. This trend is certainly evident in the nonseismic risk perception area (Dosman et al., 2001). However, trends appear to vary in the seismic risk area, other than in relation to gender and minority group status.

In locations as diverse as the US, Turkey, Romania, Japan and Morocco, females and minority groups perceive themselves to be more at risk of being affected by earthquakes than men and majority groups, respectively (Armas, 2008; Armas and Avram, 2008; Dooley et al., 1992; Karanci and Aksit, 1999; Kohiyama et al., 2008; Lai and Tao, 2003; Lindell and Prater, 2000; Mulilis, 1999; Palm, 1998; Paradise, 2006; Spittal et al., 2008; Turner et al., 1986). This confirms predictions made by cultural cognition and system justification theory. However, the links between socioeconomic status (SES) and risk perception are somewhat irregular. On the one hand, indications of higher SES, such as income, education and home ownership have been linked to decreases in risk estimates in US respondents (Farley, 1998; Lindell and Prater, 2000). On the other, a number of studies have linked increasing educational attainment of residents in moderately developed countries to higher risk perceptions (Armas and Avram, 2008; Paradise, 2006; Rüstemli and Karanci, 1999).

Older people are less likely to see earthquakes as a risk when compared with younger people (Dooley et al., 1992; Farley, 1998; Heller et al., 2005; Lai and Tao, 2003; Palm, 1998; Rüstemli and Karanci, 1999; Simpson-Housley and Curtis, 1983; Spittal et al., 2008; Turner et al., 1986). This runs contrary to a number of results from studies on risk perception of other safety hazards (e.g., Dosman et al., 2001; Kraus et al., 1992). One possible explanation is that elderly people living in seismic risk zones but in relatively secure social circumstances have survived more earthquakes than younger people, and that these experiences have made seismic risk less novel, in effect making earthquakes seem less threatening (see Sect. 3.1). One might further hypothesise that this normalising effect disappears in circumstances of severe socioeconomic and physical vulnerability, when the sense of control might lessen, thereby increasing risk perception. This is borne out by surveys of residents in extremely vulnerable parts of Bucharest, which found that age and seismic risk perception were positively correlated (Armas, 2006; Armas and Avram, 2008). Thus it is important to note that different status markers (e.g., being old and poor) are likely to interact with one another in relation to seismic risk perception. There seems to be a connection between experience of past events, power and risk perception.

\subsection{Material risk factors and seismic risk perception}

Material risk, defined as risk conceptualised scientifically as a probabilistic statement regarding degree of future hazard and exposure, may play a role in seismic risk perceptions. Lindell and Prater (2000), for example, reported that compared to residents of western Washington, southern Californians estimated their seismic risk to be greater, a risk estimation that is consistent with scientific estimates of seismic risk in the two areas. Similar findings from the US Mid-West were reported by Farley (1998).

Turkish and Romanian researchers have also looked at links between material risk and risk perception. They have found that the type (block/condominium versus single house), height, age and perceived structural vulnerability of respondents' residences, as well as respondents' knowledge of proximity to soft soils and faults, all heighten risk perceptions (Armas and Avram, 2008; Karanci and Aksit, 1999; Kasapoglu and Ecevit, 2004a; Rüstemli and Karanci, 1999). However, Lehman and Taylor (1987) reported that the risk perceptions in two groups of US students living in two dormitories that had poor and good seismic resistance respectively did not vary. Indeed, both groups, despite being aware of the seismic risk, denied being at personal risk in the event of an earthquake. While these findings may be artefacts of highly individualist motivations and optimistic biases of the US respondents, on the basis of available data it is difficult to judge whether risk perceptions vary consistently as a function of material risk. Future research should pay greater attention to relations between subjective risk perceptions and expert estimates of material risk.

A further set of studies demonstrate the importance of treating the material and built environment not merely as the origin of exposure or hazard, but as a source of meaning for the people who live in it. Research in environmental psychology (Stedman, 2002) and consumer psychology (Belk, 1988) shows that places and possessions are integral parts of human identities, and that the meanings people attach 
to them, as well as their sense of satisfaction with them, have implications for responses to threats of damage or loss. For instance, strong attachment to and low satisfaction with homes and possessions might drive risk concerns as well as place-protective motivations (Stedman, 2002, 567-568). Conversely, low attachment and high satisfaction might diminish motivations to be concerned with risks. For example, in Stedman's research (2002, 575-576), strong attachment to, and low satisfaction with a recreational area predicted behavioural intentions to oppose environmentally degrading changes to that place.

While the research on seismic risk perception has assumed that people positively identify with, feel strongly attached to and are satisfied with their home environments and possessions, this cannot be taken for granted. This might especially be the case in less socio-economically developed areas, unstable and insecure areas, or places with high migration, rapid rates of urbanisation and high proportions of informal/illegal housing. In these areas it might well be that place identification, attachment and satisfaction are highly variable, and that these factors interact with risk perceptions and concerns. Future researchers should take these considerations into account.

\subsection{Influence of seismic risk perceptions on seismic adjustment behaviour}

A critical issue in the discussion of risk perception is how it relates to risk protective behaviour. A number of studies have reported positive correlations between risk perceptions and seismic adjustment (e.g., Flynn et al., 1999; Jackson, 1981; Lindell and Prater, 2000; Palm and Carroll, 1998; Turner et al., 1986), in essence claiming that stronger concern regarding seismic risk motivates seismic adjustment more than weaker concern. However, these associations have often been of a small magnitude (e.g. Rüstemli and Karanci, 1999). In addition, they usually relate only to certain types of adjustments - generally response and recovery-related items with utility mainly for the post-impact phase (Kirschenbaum, 2005; Palm and Carroll, 1998).

While Lindell and Perry's (2000) overview of household adjustment to seismic risk indicated that higher risk perception tends to lead to subsequent adjustment, later work has partially disconfirmed this proposition (Lindell and Prater, 2000, 2002; Lindell and Whitney, 2000; Perry and Lindell, 2008; Whitney et al., 2004). This is corroborated by Armas and colleagues (Armas, 2006; Armas and Avram, 2008). It seems from existing studies that risk perception is only weakly related to seismic adjustment. Thus, once the literature on risk perception has been summarised, the paper moves on to consider what factors, beyond risk perceptions, shape seismic adjustment.

\subsection{Summary}

In summary of social psychological work on seismic risk perception, experience certainly plays a role in the salience that earthquakes have for people. However, a significant proportion of people in seismically active areas do not manifest ongoing concern about their vulnerability. Indeed, they seem to prioritise other risks, and to manifest optimistic bias in relation to being affected by future earthquakes. Furthermore, regarding demographic factors, females, minority group members and younger people see themselves to be more at risk of earthquakes than males, majority group members and older people respectively. Findings concerning links between seismic risk perception and socio-economic status are more equivocal. It is also difficult to judge, from the literature available to date, whether risk perceptions vary consistently as a function of material risk. Finally, risk perception is weakly related to seismic adjustment, particularly regarding response and recovery related adjustments.

\section{Further factors shaping seismic adjustment}

Beyond risk perception, what shapes seismic adjustment? The following section will evaluate the literature concerning how norms and social identities shape seismic adjustment. Furthermore, research concerning the role played by trust and responsibility will be examined. Finally, the extensive literature on the roles played by control, self-efficacy and fatalism in seismic adjustment will be assessed.

\subsection{Norms and social identities}

The paper has argued that social structural variables such as age, gender, ethnicity and status influence the content and strength of seismic risk perceptions. These categories are also used by individuals to categorise themselves and others: "Social identity is that part of the self concept that derives from group membership" (Fiske, 2004, p. 475). Categorisation of self and others into common social identities is a primary strategy that people use to enhance cohesion with their peers and their community (Fiske, 2004, pp. 483-484; Joffe and Staerkle, 2007). These social categories include norms for individual and group behaviours. Norms are rules for behaviour in a culture or for segments thereof. Inasmuch as groups actively endorse or passively impose normative behaviours on their members, social identities influence both attitudes and behaviour (Terry et al., 1999; White et al., 2009).

Thus, norms have a bearing on seismic adjustment behaviour. Norms derive from people's perceptions of others' behaviours, irrespective of whether these are approved of or not. They also derive from perceived outcomes of behaviours. An example would be individuals seeing that their neighbours had installed latches on their cupboard doors, with the understanding that the contents of the cupboards 
would not fall out in the event of an earthquake. Norms can also be conceptualised as those shared beliefs that explicate rules for good, bad and permissible behaviour. For example, seismic risk communication messages typically contain information about types of behaviours that risk communicators would like audiences to engage in (e.g., duck, cover and hold). The force of such explicit norms depends on the degree to which people identify with the groups that espouse them (Terry et al., 1999), and how competent and trustworthy these groups are perceived to be. Despite the theoretical and practical importance of norms for seismic adjustment behaviour, relatively few studies have explicitly concerned themselves with the causal effect of norms.

From the basic assumption that behaviour is shaped by social identities and norms, one would expect that people's seismic adjustment attitudes and decisions are influenced by whether and how they see and hear social reference groups attending and responding to seismic risk information. Since earthquakes are infrequent and unpredictable events, people face a large degree of uncertainty and ambiguity when deciding whether and how to attend to risk communications on seismic activity. One of the main strategies people use to deal with uncertainty is to seek information from experts, peer groups and public communications such as the mass media. In part, this allows them to gauge whether their responses to risks correspond with socio-cultural norms and values. By following what members of their reference group say and do people ensure that they behave in ways that are congruent with their own and society's expectations of them.

In support of such theory, Mileti and Fitzpatrick (1992; also Mileti and Darlington, 1997) reported that seismic adjustments in their sample increased when respondents observed other people adjusting. Similarly, Farley (1998) showed that believing that one's neighbours were prepared predicted more adjustment, whereas the belief that neighbours did not know how to prepare led to less adjustment. Seismic adjustments increase when information sources providing explicit norms for adjustments are numerous, consistent and specific (Mileti and Darlington, 1997; Mileti and Fitzpatrick, 1992; Mileti and O'Brien, 1992). These results suggest that seismic adjustment is partly an outcome of the norms that people infer from the behaviour and communications of community members.

A range of research suggests that gender plays a role in seismic adjustment, as shown by the clear gender differences in risk perception. Furthermore, Mulilis (1999) found stable and consistent differences in adjustment activities between females and males that apparently reflected traditional US gender norms regarding labour divisions. While males were significantly more likely to know about the location and operation of household utilities, females were more likely to engage in mitigation and planning activities such as securing the contents of the home, gathering hazard information and making household emergency plans. According to Mulilis, female participants rated earthquakes as a greater threat, and this was responsible for gender differences in adjustment patterns. An alternative explanation is that cultural norms regarding gender-appropriate tasks were responsible for these differences.

Hazards and health threats are commonplace conversation topics in families and among neighbours, friends and colleagues. This might have an impact on risk adjustment. Informal discussion of earthquake topics, attendance at community earthquake preparedness meetings and the presence of strong and long-lasting ties to the community were all significant predictors of adjustment in the Turner et al. (1986) surveys. Further support for this hypothesis comes from Heller et al. (2005) who found that in families where helping behaviour was common-place, higher levels of hazardrelated discussion predicted adoption of seismic mitigation adjustments. These results suggest that social networks have an effect on seismic adjustment adoption; dense, durable and pro-social community ties promote rapid and strong norm enforcement, as well as ample opportunity for observational learning, both of which steer people towards making seismic adjustments. However, it must be pointed out that this process depends on the content of the norms. If these norms militate against making adjustments then strong ties might stifle positive adjustments. Future research might look at how household and community norms that sanction adjustment arise and are maintained, as well as their ultimate effect on adjustment rates.

The above discussion suggests that, beyond risk perception, seismic adjustment can be influenced by social identity and norms. It can also be influenced by trust and responsibility. These factors are elaborated below.

\subsection{Trust}

In a number of countries community planning in general, and emergency management and disaster resilience building in particular, are arenas filled with increasingly professionalised, specialised and politicised actors (Burby, 2003; Godschalk et al., 2003; Waugh, 1999). These developments can create distance between the emergency planners/decision-makers and the public they serve, which can result in loss of trust (Waugh, 1999). Despite these warnings found in the literature, and the prominence of trust issues in psychology in general, only a handful of studies have looked at trust in the context of individual and household seismic adjustment.

Trust is a crucial factor underpinning adjustment adoption (Paton, 2008; Paton et al., 2010; Johnston et al., 2003). Levels of trust strongly influence whether people take hazard warnings seriously and how they deal with them. A lack of trust in civic risk managers can lead to controversy and divisiveness, thus hampering efforts to enhance individual and social resilience (Slovic, 2000). Trust becomes significant for seismic adjustment where there is little public information about the hazard and the hazard is relatively novel 
(Paton, 2008). In this situation communities seek a collective articulation of the problems of risk management, alongside an effort to become empowered relative to civic authorities. If these goals are achieved levels of trust mediate the impact that risk perception, norms and adjustment attitudes have on intention to adjust: high trust motivates intentions to adjust, low trust will dampen this motivation.

Paton's (2008) concept of trust refers to aspersion of competence. Yet trust is also a morally and culturally important emotion, where the attribute being evaluated is moral integrity. Responses to corruption, defined as betrayal of communal trust and transgression of individual rights, highlights this moral dimension. Not only does corruption elicit the moral emotion of disgust, as well as contempt and anger (Rozin et al., 1999), it also correlates with relatively higher earthquake-related death tolls (Anbarci, Escaleras and Register, 2005; Escaleras, Anbarci and Register, 2007).

Fieldwork among squatters in Istanbul revealed the consequences that lack of trust may have on seismic adjustment. Public distrust of expert seismic adjustment advice arises when acts of the Turkish construction industry, engineers and regulatory bodies are seen to be corrupt (Green, 2008). Members of households feel that these entities have betrayed the wider society by knowingly and willingly letting monetary and political benefits take precedence over diligence and moral integrity. Among Turkish land squatters this leads to increased reliance on and valorisation of vernacular construction knowledge and practices that differ significantly from officially sanctioned best practice. House-building is therefore contracted out to people who are perceived to be noncorrupt and competent (but often are not), undertaken by the prospective owners themselves, or proceeds as a mix of the two. Green (2008) proposes that Istanbul's extensive selfbuilt housing stock increases the vulnerability of its citizens, and that lack of trust between lay and expert groups is partly to blame.

In a recent survey of a Californian sample, Basolo et al. (2009) tested the notion that people's levels of confidence in the government's competence to protect them would lead to changes in household adjustment levels. Among their Los Angeles County respondents $45.1 \%$ had high levels of confidence in government competence. Those with high confidence in the competence of the government to protect them from earthquakes were three times more likely to rate their own adjustment rates as high when compared to those with low levels of confidence, even though there were no differences in actual seismic adjustment levels. This finding is interesting yet difficult to interpret. More work is needed to clarify the roles that confidence and trust play in motivating seismic adjustment. The question of which people, groups and institutions are deemed competent seems to be culturally as well as individually variable (Rozin et al., 1999). Individuals' and households' attitudes towards adjustment and risk are shaped by wider attitudes towards political authorities, scientific and technical experts, the mass media, community-based and non-governmental organization and other households, among others (Lindell et al., 2007; Drabek, 1986).

\subsection{Responsibility}

Attributions of responsibility are further shapers of seismic adjustment. Evidence from surveys on the West coast of the US indicates that attributions of responsibility for protection from earthquakes has shifted from government to individual responsibility over time. Jackson (1981) reported that only $10.6 \%$ of his respondents believed that private individuals and households had primary responsibility for seismic adjustment, while the remainder of the responsibility lay with various levels of government. Similarly, Turner et al. (1986) found that local, state and federal government was seen as responsible for the protection of groups in danger of earthquakes by more than $60 \%$ of their respondents. Garcia (1989, from Lindell and Perry, 2000) found that in the period from the early to late 1980 s, Californians seemed to have radically changed their attributions of responsibility, with $98 \%$ believing seismic adjustment was an individual or household responsibility. Thus there appears to be a shift to seeing the individual, as opposed to broader institutions, as responsible for seismic adjustments, at least in the North American context. In this vein, Arlikatti, Lindell and Prater's (2007) recent study found that the self and family were judged to have the greatest responsibility for seismic adjustment.

US surveys have shown that home ownership, length of community residence and the presence of children or dependents all increase seismic adjustment (Duval and Mulilis, 1999; Turner et al., 1986). This suggests that home owners, as compared to renters, are more motivated to undertake what can be costly and time-consuming adjustment measures. Also, based on their greater legal duties towards the maintenance of housing, one would expect them to feel more responsible for the safety of their residence than renters.

The causal chain leading from individual risk perception to increased seismic adjustment motivation might be partially contingent on the presence of cultural and political norms stating that the individual or the household should have some responsibility for seismic adjustments. Japanese respondents differed in responsibility attributions relative to Californian respondents in Palm and Carroll's surveys (1998): the authors argue that Japan's cultural emphases on social collectivism and hierarchy led Japanese people to ascribe more adjustment responsibility to governments and experts than did Californians. This had consequences for household adjustment: while the Japanese had stronger risk perceptions, they made fewer adjustments than their US counterparts.

On the basis of the empirical results reviewed above it seems reasonable to assume that attributions of responsibility influence seismic adjustment. This may occur in one of two ways (see Terry et al., 1999). Firstly, if a group with which one identifies strongly expects that all group members should 
assume, and act on, seismic adjustment responsibilities, the desire to conform to the group will lead to greater adoption of group-normative seismic adjustment. The strength of identification with a group will influence the extent to which individuals conform to group norms. Secondly, individuals may feel that seismic adjustment responsibility is an important part of their self-identity, regardless of group norms. If seismic adjustment responsibility is important for self-identity it is more likely that seismic adjustments will be adopted, relative to cases where such responsibility is not seen as an important part of self-identity.

\subsection{Control, efficacy and fate}

Self-efficacy is one's perception that one has the ability to effectively decrease or control a threat. One's sense of control stems from attitudes towards ones knowledge, skills and other resources required to allay the threat (Lindell and Whitney, 2000) as well as one's perception of the efficiency of the adjustments themselves. Social and cultural factors such as mass media and other public discourses shape attitudes towards efficacy. Research shows that such discourses concerning protection efficacy are sometimes highly fatalistic, and that individuals might come to believe that any effort to protect themselves are doomed to fail. Where notions of control, as opposed to fatalism, dominate, most individuals realise that protection from earthquake risks relies on cooperative efforts at local, regional and national levels (Paton, 2008; Paton et al., 2010). This paper deals with these factors in turn. First, causes and consequences of selfefficacy will be examined. Next the issue of collective efficacy and empowerment will be dealt with. Finally, research on fatalism and negative control beliefs will be evaluated.

\subsubsection{Individual attitudes towards control}

What motivates people to adjust to seismic risk? One motivating force is knowledge that leads to the belief that one can control the outcome of the earthquake, that is, self-efficacy. McClure and colleagues (Cowan et al. 2002; McClure et al., 1999, 2001, 2007a,b) have shown that certain characteristics of information about earthquake damage, as presented via mass media reports for example, can shape attitudes towards preventability. Specifically, reports that provide accurate, rate-based information about why one type of building withstood ground-shaking whereas another type collapsed enables people to understand that building design is a major cause of losses, allowing them to infer more easily that losses are controllable. They have also shown that people who are told that they live in a low risk zone judge damage to be more preventable than those who are told they live in a high risk zone. Thus exposing people in high-risk zones to information about their vulnerability may lead them to either deny this, or to evolve fatalistic attitudes. Finally, they have shown that obtaining knowledge that is complex and com- mensurate with scientific understanding is likely to increase perceptions of adjustment efficacy (Hurnen and McClure, 1997; also Gruev-Vintila and Rouquette, 2007). These findings contribute to the argument that individual beliefs about control and outcome in relation to seismic risks are shaped by cultural discourses such as those presented in mass media and popular culture.

Steinberg (2000), Fradkin (2005) and Rozario (2007), who have examined the history of disaster narratives in the US, argue that the dominant representation of disasters in US mass media, popular culture and political discourse has been one where earthquakes are presented as "acts of God", and latterly "acts of Nature". In these discourses, as in the messages studied by McClure and colleagues, the cause of damage is attributed to the unpredictable and uncontrollable forces of nature rather than to the actions of human beings. This has the consequence of eliding the role played by powerful market actors, such as property developers, aided by a market friendly regulatory state, in inequity and vulnerability.

Studies on individual control and efficacy relating to seismic adjustment reveal that both cognitive and cultural factors determine the contents of individuals' control beliefs. Messages that highlight the scope for human agency in seismic risk reduction play a role in allowing people to feel that they can control their risks. However, wider cultural discourses often militate against such interpretations of human agency, as future sections will highlight.

\subsubsection{Collective efficacy and empowerment}

For the most part, people do not live in isolation, and desirable outcomes, such as seismic adjustment, are only fully achieved through interaction with other individuals and groups (Bandura, 2000). When faced with uncertainty people turn to similar others for support and information on what to think, feel and do. This can be termed collective efficacy. It refers to people's joint ability to identify risks and implement seismic adjustments. Paton and colleagues (Paton, 2008; Paton et al., 2010) have examined how beliefs about collective efficacy and perceptions of inter-group fairness and empowerment affect intentions to adopt seismic adjustments among at-risk people in New Zealand and Japan. Results from both New Zealand and Japan indicate that collective efficacy has a positive influence on seismic adjustment intentions.

When communal knowledge and resources concerning earthquake preparedness are seen as insufficient, people seek help from powerful and expert sources such as scientists and emergency management organisations (Paton et al., 2010). In other words, the community seeks empowerment. Empowerment is achieved only if these sources are seen as trustworthy, treat the community with respect and fairness, and respond in ways that are consistent with the needs and expectations of community members. Results from these studies suggest 
that collective efficacy in itself has a positive effect on empowerment and empowerment has a positive influence on adjustment intentions, if the experts are trusted.

It is clear from Paton's studies that collective efficacy and empowerment have a positive effect on seismic adjustment rates, but are affected by the individualist or collectivist nature of the culture. In New Zealand the belief in personal control over the outcomes of earthquakes predicts levels of collective efficacy and empowerment. This was not the case in Japan. Here, results indicated that self-efficacy had no impact on either collective efficacy or empowerment. This, argues Paton and colleagues, illustrates the greater importance of mutualism, interdependence and collectivist social action in Japanese society.

\subsubsection{Fatalism}

An early and persistent finding in disaster research is that many respondents display an attitude of fatalism towards disaster risk and its mitigation. Psychologically, fatalism entails the perception that there is little or nothing one can do to avoid or protect oneself from risk, and that the locus of control over life events is external to oneself (McClure et al., 1999). Specifically, earthquake fatalism implies that the causes of damage are attributed to the force of the earthquake alone, rather than to building design or other controllable factors (McClure et al., 2001).

For scientists the question, "What is an earthquake?" evokes no fundamental ambiguity. However, lay interpretations of the earth's activity differ in significant ways from scientific knowledge, not only in terms of the hazard it poses, but also regarding what causes it. This has implications for beliefs regarding the degree of control people believe they possess in relation to seismic adjustment. In US surveys the belief that the theological significance (i.e., sinfulness) of individual or societal actions can cause an earthquake has been espoused by a minority of respondents, both in the past and the present (Rozario, 2007; Turner et al., 1986). A German study also indicated a limited, yet significant belief that earthquakes were caused by God's punishment or by nature taking revenge (Plapp and Werner, 2006). Theological explanations of earthquakes are prevalent in some Muslim communities, where earthquakes have a special religious and scriptural significance as instances of divine manifestation and retribution, and as precursors of Judgment Day (Kasapoglu and Ecevit, 2004b; Paradise, 2005). Historically, ground-shaking has prompted communities to create mythical narratives to explain its occurrence, and many of these survive to the present day, both in parallel to and as competitors with, scientific narratives. Evidence on how these two systems of knowledge interact, and how that interaction affects control-related beliefs concerning seismic adjustment is virtually non-existent.
Studies have shown that inasmuch as they impact on behaviour, fatalistic attitudes are major obstacles to disaster risk reduction efforts; they reduce or obviate the motivation to take warnings seriously and the intention to engage in adjustment behaviours. When fatalism is coupled with an optimistic bias, there is even less of a chance that people will attend to and prepare for natural hazards (Lehman and Taylor, 1987). Whereas some evidence suggests that religious beliefs regarding preordained destiny or supernatural causation might facilitate the formation of fatalistic attitudes, the results published by McClure and his colleagues, summarised in Sect. 4.4.1, suggest that religious beliefs cannot a priori be assumed to be sufficient or necessary for this to occur.

Turner et al. (1986) were among the first to study earthquake fatalism systematically. Somewhat contrary to representations of North Americans as resourceful, self-reliant and optimistic, they found that three out of five were fatalistic about preparing for the general consequences of an earthquake, and one in three was fatalistic about their opportunities to mitigate the risk. In their analysis of the causal pathways leading to preparedness they found that fatalism was positively correlated with membership of an ethnic minority, but negatively correlated with education. The relationship between fatalism and seismic adjustment, as expected, was strongly negative. This was corroborated in surveys from the central USA (Farley, 1998). Beyond this context, Asgary and Willis' (1997) survey of residents of the Iranian cities Teheran and Rasht found that almost half would do nothing on being reliably informed of an imminent earthquake risk. A fatalistic attitude among their respondents was the strongest predictor of the lack of intention to adjust to seismic risk. Clearly, fatalistic ideas diminish protection motivation in at-risk people.

Flynn et al. (1999) showed that approximately half of their sample of Portland, Oregon residents did not believe there was much they could do about earthquakes. The other half thought they had some control over their exposure, but crucially, a strong majority $(74.8 \%)$ believed that it was their city or community that could lessen earthquake damage. This partial fatalism was further reflected in findings that showed relatively strong support for city-led risk reduction actions targeting community emergency preparedness facilities and vulnerable or critical populations and structures. These findings suggest that fatalism cannot purely mean "feeling that one lacks control over one's environment". Rather the concept of fatalism, like efficacy (see above section), should be re-defined so as to encompass not just the relationship between an individual household and natural hazards, but also the ties that empower or disempower individuals and households relative to institutional forces. The structural theories of recent social psychological research, such as cultural cognition, system justification and others - are well suited to examine the roles of power, control and helplessness at individual, group and societal levels. They can furthermore account for known cultural and geographical differences in risk 
concerns and risk responses, as these may arise from cultural variations in individualism versus collectivism and authoritarianism versus egalitarianism (see Sect. 3.1).

\subsection{Summary}

In summary of Sect. 4 of this re-evaluation, seismic adjustment is partly an outcome of the normative behaviours that people infer from the behaviour of fellow community members. It is also shaped by cultural norms regarding genderappropriate roles and tasks. People match their behaviour to those around them and if the norms prescribe positive adjustments these are followed, but if those to whom one has close social ties do not endorse making adjustments, then this example is followed. Trust is a crucial factor underpinning adjustment adoption. In contexts where people rely on expert advice, high levels of trust in this advice will motivate people to adopt adjustments. Low trust will dampen this motivation. In addition, corruption, which can be defined as betrayal of communal trust, leads people to take building matters into their own hands, which can be detrimental to the their seismic vulnerability. Furthermore, attributions of responsibility for protection from earthquakes has shifted from governments to individuals over the past decades, at least in the North American context. US surveys have also shown that home ownership, length of community residence and the presence of children or dependents all increase seismic adjustment. Responsibility is also shaped by cultural factors: the greater emphasis on collectivism and hierarchy in Japan, for example, leads Japanese people to ascribe more responsibility for seismic adjustments to their government, than North Americans ascribe.

Beyond issues pertaining to norms, trust and responsibility, the section indicates that an understanding that building design influences earthquake losses enhances beliefs in control. More generally, obtaining knowledge that is complex and commensurate with scientific understanding is likely to increase perceptions of adjustment efficacy. However, in the dominant representation of disasters, earthquake losses are seen as 'acts of nature' rather than "acts of human beings". Beyond individual factors, collective efficacy has a positive effect on empowerment and empowerment tends to have a positive influence on adjustment intention, if relations between communities and authorities are trusting and respectful. Studies have shown that inasmuch as they impact on behaviour, fatalistic attitudes are major obstacles to disaster risk reduction efforts; they reduce or obviate the motivation to take warnings seriously and the intention to engage in adjustment behaviours.

\section{Discussion and considerations for future research}

Literature on the social psychology of hazard adjustment paints a somewhat equivocal picture of the importance of risk perceptions as well as norms, attributions of trust and responsibility, and attitudes towards control, fatalism and efficacy in the making of seismic adjustments. The data suggest that these factors are moderated by social, cultural and political factors. Yet the literature is highly skewed towards studies from the US and New Zealand. To ascertain the causal pathways leading to seismic adjustment on the part of individuals and households similar work would need to be conducted in a wider array of countries. Since existing studies adopt different measures of seismic adjustment and of psychological factors, thereby making direct comparisons difficult, it would be desirable for the field to synchronise its measures.

There are few cross-cultural studies of seismic adjustment. Palm and Carroll's (1998) US-Japanese research is a notable exception. Future studies employing structural social psychological models (e.g., cultural cognition, system justification) would readily speak to the broader issues constraining household responses to seismic hazards. The recent studies by Paton et al. (2010) and Paton et al. (2010) are exemplary beginnings of this new direction.

A striking finding is that a majority of the studies in the field are based solely on homeowners. Although the reasons for this are clear - they are most likely to have the opportunity to make structural adjustments and run a greater risk of incurring personal financial losses - other populations' adjustment behaviours and risk perceptions are largely opaque. Future work must redress this imbalance since many non-homeowners die in earthquakes because they have not adopted adjustments that were feasible for them and would have saved them.

The above discussion highlights some of the gaps in current empirical work. However, there are a further set of problems with the assumptions made within the social psychological research that is reviewed. The vast majority of the studies assume that the most important causes of seismic adjustment can be conceptualised as mental processes that take place primarily within the individual mind. These processes are further assumed to be primarily consciously available cognitive representations of risks, norms, control and so on. Thus individualist and rationalist assumptions have dominated the research evaluated in this paper, reflecting those pervading the broader discipline of social psychology. Despite its name, much North American and European social psychology adopts a narrow focus: inter-individual influences on intra-individual cognitive processes.

The wider contexts of hazard representations and responses to vulnerability have been largely neglected in psychological models of seismic adjustment. Household adjustment to earthquakes emerges from the position of the household in the larger social system in which it is embedded. 
Constraints on households' capacity to adjust, and thus their resilience and vulnerability, is primarily, albeit not exclusively, determined by access to informational, social, economic and political resources (Bankoff et al., 2004; Wisner et al., 2004). Household seismic adjustment, such as decisions to reinforce homes, make plans, learn skills and store basic material amenities, is ultimately a systemic consequence of factors ranging from the social psychological to the economic, from cultural dynamics of equity to issues of power. A small, but increasingly prominent minority of social psychologists argue for the centrality of cultural identities, intergroup relations, ideologies, emotions and social representations (e.g., Hogg and Smith, 2007; Joffe, 1999, 2003; Jost et al., 2004; Kahan et al., 2007; White et al., 2009) in people's responses to risks. Such more inclusive models have the capacity to engage researchers interested in an interdisciplinary approach to seismic adjustment.

\section{Conclusions}

Despite many equivocal findings, the literature has highlighted clear correlations between adjustment adoption and a number of social psychological factors. Importantly, risk perception is shaped by experience, optimism and demographic factors including gender, majority/minority group status and age. Contrary to received wisdom, this paper argues that risk perception correlates only weakly with seismic adjustment. Seismic adjustment is also an outcome of group norms that are transmitted by the media and other actors in people's social environments. Seismic adjustment is also linked to the extent to which relevant experts are trusted and how responsibility for earthquakes is constructed. Finally, people's sense of their individual and collective control over adjustments and their sense of efficacy and fate in relation to the impact of the earthquake shape whether seismic adjustments are adopted or not. All of these factors are sensitive to local cultural and political contexts. These should be considered in disaster risk reduction planning and implementation as a means to increase the uptake of seismic hazards adjustments. Educational material that provides information on seismic adjustments must be designed in a way that reduces both fatalistic and overly optimistic attitudes to earthquake losses. Choosing effective means of information dissemination, via sources seen to be responsible, trusted and culturally congruent by the audience, should be best practice. The facilitation of participant-led discussions on emergency planning and response in communities, in order to increase its members' sense of empowerment, understanding and responsibility must have a strong role in risk reduction efforts. These efforts need to be grounded in and progressively refined by a scientific understanding of the causes of individual, household and societal seismic adjustment.

Researchers interested in social psychological drivers of individual and household seismic adjustment also need to connect with the broader processes that impact on resilience, vulnerability and adjustment. The ways in which persistent inequalities in access to resources, and deficits in democratic participation in decision-making regarding seismic risk issues are motivated, justified and reproduced, can be addressed by social psychological theories (e.g., Jost et al., 2004; Kahan et al., 2007). Issues of cultural identity, power and trust need to be brought centre stage. Their absence in much of the literature speaks to a profound theoretical limitation, grounded in late modern political and cultural frames. These seek to explain behaviour as if it was purely a matter of (ir)rational individual choice in a controllable world. Rationalistic and individualistic perspectives bring some useful concepts to the field. However, without acknowledging the theoretical limitations and practical implications of these perspectives, the international communities of disaster risk researchers and the practitioners who look to their work will never reach a satisfactory explanation of the complex relations between individuals, organisations, societies and earthquakes. Neither will they properly address the root causes of seismic adjustment.

Acknowledgements. The present study has been generously supported by the EPSRC grant no. EP/F012179/1. The authors would also like to thank the referees for their careful and constructive critiques.

Edited by: F. Guzzetti

Reviewed by: S. Cornell and another anonymous referee

\section{References}

Anbarci, N., Escaleras, M., and Register, C. A.: Earthquake fatalities: the interaction of nature and political economy, J. Public Econ., 89(9-10), 1907-1933, 2004.

Armas, I.: Earthquake risk perception in Bucharest, Romania, Risk Anal., 26(5), 1223-1234, 2006.

Armas, I.: Social vulnerability and seismic risk perception. Case study: the historic center of the Bucharest Municipality/Romania, Nat. Hazards, 47(3), 397-410, 2008.

Armas, I. and Avram, E.: Patterns and trends in the perception of seismic risk. Case study: Bucharest Municipality/Romania, Nat. Hazards, 44(1), 147-161, 2008.

Arlikatti, S., Lindell, M. K., and Prater, C. S.: Perceived stakeholder role relationships and adoption of seismic hazard adjustments, International Journal of Mass Emergencies and Disasters (IJMED), 25(3), 218-256, 2007.

Asgary, A. and Willis, K. G.: Household behavior in response to earthquake risk: an assessment of alternative theories, Disasters, 21(4), 354-365, 1997.

Bandura, A.: Exercise of human agency through collective efficacy, Curr. Dir. Psychol. Sci., 9(3), 75-79, 2000.

Bankoff, G., Frerks, G., and Hilhorst, D.: Mapping vulnerability: disasters, development and people, Earthscan, London, UK, 2004.

Basolo, V., Steinberg, L. J., Burby, R. J., Levine, J., Cruz, A. M., and Huang, C.: The effects of confidence in government and 
information on perceived and actual preparedness for disasters, Environ. Behav., 41(3), 338-364, 2009.

Belk, R. W.: Possessions and the extended self, J. Consum. Res., 15(2), 139-168, 1988.

Bendix, R.: Reflections on earthquake narratives, Western Folklore, 49(4), 331-347, 1990.

Burby, R. J.: Making plans that matter: citizen involvement and government action, J. Am. Plann. Assoc., 69(1), 33-49, 2003.

Burger, J. M. and Palmer, M. L.: Changes in and generalization of unrealistic optimism following experiences with stressful events: reactions to the 1989 California earthquake, Pers. Soc. Psychol. B., 18(1), 39-43, 1992.

Celsi, R., Wolfinbarger, M., and Wald, D.: The effects of earthquake measurement concepts and magnitude anchoring on individuals' perceptions of earthquake risk, Earthq. Spectra, 21(4), 87-1008, 2005.

Clarke Guarnizo, C.: Living with hazards: communities' adjustment mechanisms in developing countries, in: Environmental management and urban vulnerability, edited by: Kreimer, A. and Munansinghe, Y. M., The World Bank, Washington DC, USA, 93-106, 1992.

Comerio, M. C.: Public policy for reducing earthquake risks: a US perspective, Build. Res. Inf., 32(5), 403-413, 2004.

Cowan, J., McClure, J., and Wilson, M.: What a difference a year makes: how immediate and anniversary news reports influence judgments about earthquakes, Asian J. Soc. Psychol., 5(3), 169$185,2002$.

Cutter, S. L., Boruff, B. J., and Shirley, W. L.: Social vulnerability to environmental hazards, Soc. Sci. Quart., 84(2), 242-261, 2003.

Dooley, D., Catalano, R., Mishra, S., and Serxner, S.: Earthquake preparedness: predictors in a community survey, J. Appl. Soc. Psychol., 451-470, 1992.

Dosman, D. M., Adamowicz, W. L., and Hrudey, S. E.: Socioeconomic determinants of health- and food safety-related risk perceptions, Risk Anal., 307-317, 2001.

Drabek, T. E.: Human system responses to disaster: an inventory of sociological findings, Springer-Verlag, New York, NY, USA, 1986.

Douglas, M. and Wildavsky, A.: Risk and culture. An essay on the selection of technological and environmental dangers, University of California Press, Berkeley, CA, USA, 1983.

Duval, T. S. and Mulilis, J.-P.: A Person-Relative-to-Event (PrE) approach to negative threat appeals and earthquake preparedness: a field study, J. App. Soc. Psychol., 29(3), 495-516, 1999.

Er, N.: A new flashbulb memory model applied to the Marmara earthquake, Appl. Cognit. Psychol., 17(5), 503-517, 2003.

Escaleras, M., Anbarci, E., and Register, C. A.: Public sector corruption and natural disasters: a potentially deadly interaction, Public Choice, 132(1-2), 209-230, 2007.

Farley, J. E.: Earthquake Fears, Predictions, and Preparations in Mid-America, Southern Illinois University Press, Carbondale, IL, USA, 1998.

Feygina, I., Jost, J. T., and Goldsmith, R. E.: System justification, the denial of global warming, and the possibility of "systemsanctioned" change, Pers. Soc. Psychol. B., 36(3), 326-338, 2010.

Fiske, S. T.: Social beings: a core motives approach to social psychology, Wiley, New York, USA, 2004.
Flynn, J., Slovic, P., Mertz, C. K., and Carlisle, C.: Public support for earthquake risk mitigation in Portland, Oregon, Risk Anal., 19(2), 205-216, 1999.

Fradkin, P. L.: The great earthquake and firestorms of 1906: how San Francisco nearly destroyed itself, University of California Press, Berkeley and Los Angeles, CA, USA, 2005.

Garcia, E. M.: Earthquake preparedness in California: a survey of Irvine residents, Urban Resources, 5, 15-19, 1989.

Godschalk, D. R., Brody, S., and Burby, R. J.: Public participation in natural hazard mitigation policy formation: challenges for comprehensive planning, J. Environ. Plann. Man., 46(5), 733754, 2003.

Green, R.: Unauthorised development and seismic hazard vulnerability: a study of squatters and engineers in Istanbul, Turkey, Disasters, 32(3), 358-376, 2008.

Gruev-Vintila, A. and Rouquette, M.-L.: Social thinking about collective risk: how do risk- related practice and personal involvement impact its social representations?, J. Risk. Res., 10(4), 555581, 2007.

Heller, K., Alexander, D. B., Gatz, M., Knight, B. G., and Rose, T.: Social and personal factors as predictors of earthquake preparation: the role of support provision, network discussion, negative affect, age and education, J. Appl. Soc. Psychol., 35(2), 399-422, 2005.

Helweg-Larsen, M.: (The lack of) optimistic bias in response to the 1994 Northridge earthquake: the role of personal experience, Basic Appl. Soc. Psych., 21(2), 119-129, 1999.

Hogg, M. A. and Smith, J. R.: Attitudes in context: a social identity perspective, Eur. Rev. Soc. Psychol., 18(1), 89-131, 2007.

Hurnen, F. and McClure, J.: The effect of increased earthquake knowledge on perceived preventability of earthquake damage, Australasian Journal of Disaster and Trauma Studies, vol. 19973, available at: http://www.massey.ac.nz/ trauma/issues/1997-3/ mcclure1.htm, 1997.

Insurance Information Institute: Facts and statistics - earthquakes, available at: http://www.iii.org/media/facts/statsbyissue/ earthquakes/, last access: 23 January 2009.

Jackson, E. L.: Response to earthquake hazard: The west coast of North America, Environ. Behav., 13(4), 387-416, 1981.

Jackson, E. L. and Mukerjee, T.: Human adjustment to the earthquake hazard of San Francisco, California, in: Natural hazards: Local, national and global, edited by: White, G. F., Oxford University Press, NY, 160-166, 1974.

Joffe, H.: Risk and "the Other", Cambridge University Press, Cambridge, UK, 1999.

Joffe, H.: Risk: from perception to social representation, Brit. J. Soc. Psychol., 42(1), 55-73, 2003.

Joffe, H. and Staerkle, C.: The centrality of the self-control ethos in western aspersions regarding outgroups: a social representational analysis of stereotype content, Cult. Psychol., 13(4), 395-418, 2007.

Johnston, D. M., Karanci, A. N., Arikan, M., and Hopkins, D. C.: Residential retrofitting in Istanbul, Turkey. Social and economic considerations, paper presented at the 8th National Conference on Earthquake Engineering, San Francisco, CA, 2003.

Jost, J. T., Banaji, M. R., and Nosek, B. A.: A decade of system justification theory: Accumulated evidence of conscious and unconscious bolstering of the status quo, Polit. Psychol., 25(6), 881919, 2004. 
Kahan, D. M., Braman, D., Gastil, J., Slovic, P., and Mertz, C. K.: Culture and identity-protective cognition: explaining the whitemale effect in risk perception, Journal of Empirical Legal Studies, 4(3), 465-505, 2007.

Kahneman. D. and Tversky, A.: Prospect theory: an analysis of decision under risk, Econometrica, 47(2), 263-291, 1979.

Karanci, N. A. and Aksit, B.: Strengthening community participation in disaster management by strengthening governmental and non-governmental organisations and networks. A case study from Dinar and Bursa (Turkey), Australian Journal of Emergency Management (AJEM), 12(4), 35-39, 1999.

Kasapoglu, M. A. and Ecevit, M. C.: Effects of cultural values on the attitudes and behaviours of survivors of the 1999 earthquake in Turkey, Australasian Journal of Disaster and Trauma Studies, vol. 2004-2, ISSN: 1174-4707, available at: http://www.massey. ac.nz/ $\sim$ trauma/issues/2004-2/kaspoglu.htm, 2004a.

Kasapoglu, M. A. and Ecevit, M. C.: Comparative behavioral response to future earthquakes: The cases of Turkey and USA, Soc. Behav. Pers., 32(4), 373-382, 2004b.

Kirschenbaum, A.: Generic sources of disaster communities: a social network approach, Int. J. Sociol. Soc. Policy, 24(10/11), 94129, 2004.

Kirschenbaum, A.: Preparing for the inevitable: Environmental risk perceptions and disaster preparedness, IJMED, 23(2), 97-127, 2005.

Kohiyama, M., Kiremidjian, A. S., Meguro, K., and Ohara, M. Y.: Incentives and disincentives analysis for improving policy for seismic risk management of homeowners in Japan, Natural Hazards Review, 9(4), 170-178, 2008.

Kraus, N., Malmfors, T., and Slovic, P.: Intuitive toxicology: expert and lay judgments of chemical risk, Risk Anal., 12(2), 215-232, 1992.

Lai, J. C. and Tao, J.: Perception of environmental hazard in Hong Kong Chinese, Risk Anal., 23(4), 669-684, 2003.

Lehman, D. R. and Taylor, S. E.: Date with an earthquake, Pers. Soc. Psychol. B., 13(4), 546-555, 1987.

Lindell, M. K., Arlikatti, S., and Prater, C.: Why people do what they do to protect against earthquake risk: Perceptions of hazard adjustment attributes, Risk Anal., 29(8), 1072-1088, 2009.

Lindell, M. K. and Perry, R. W.: Household adjustment to earthquake hazard: a review of the research, Environ. Behav., 32(4), 461-501, 2000.

Lindell, M. K. and Prater, C. S.: Household adoption of seismic adjustments: a comparison of research in two states, IJMED, 18(2), 317-338, 2000.

Lindell, M. K. and Prater, C. S.: Risk area residents' perceptions and adoptions of seismic hazard adjustments, J. Appl. Soc. Psychol., 32(11), 2377-2392, 2002.

Lindell, M. K. and Whitney, D. J.: Correlates of household seismic adjustment adoption, Risk Anal., 20(1), 13-25, 2000.

McClure, J., Walkey, F. H., and Allen, M.: When earthquake damage is seen as preventable: attributions, locus of control and attitudes to risk, Appl. Psychol.-Int. Rev., 48(2), 239-256, 1999.

McClure, J., Allen, M. W., and Walkey, F.: Countering fatalism: causal information in news reports affects judgments about earthquake damage, Basic Appl. Soc. Psychol., 23(2), 109-121, 2001.

McClure, J., Sutton, R. M., and Sibley, C. G.: Listening to reporters or engineers? How instance-based messages about design affect earthquake fatalism, J. Appl. Soc. Psychol., 37 9), 1956-1973, 2007a.

McClure, J., Sutton, R. M., and Wilson, M.: How information about building design influences causal attribution for earthquake damage, Asian J. Soc. Psychol., 10(4), 233-242, 2007 b.

Mileti, D. S. and Darlington, J. D.: The role of searching in shaping reactions to earthquake risk information, Soc. Probl., 44(1), 89103, 1997.

Mileti, D. S. and Fitzpatrick, C.: The great earthquake experiment: Risk communication and public action, Westview Press, Boulder, CO, 1992.

Mileti, D. S. and O'Brien, P. W.: Warnings during disaster: normalizing communicated risk, Soc. Probl., 39(1), 40-57, 1992.

Mulilis, J.-P.: Social considerations of disaster-resistant technology: the person-relative-to- event (PrE) model of coping with threat, J. Urban Technol., 3(3), 59-70, 1995.

Mulilis, J.-P.: Gender and earthquake preparedness. A research study of gender issues in disaster management: differences in earthquake preparedness due to traditional stereotyping or cognitive appraisal of threat?, Austr. J. Emerg. Manage., 14(1), 41-50, 1999.

Mulilis, J.-P. and Lippa, R.: Behavioral change in earthquake preparedness due to negative threat appeals: a test of Protection Motivation Theory, J. Appl. Soc. Psychol., 20(8), 619-638, 1990.

Neisser, U.: Remembering the earthquake: direct experience vs. hearing the news, Memory, 4(4), 337-357, 1996.

Nguyen, L. H., Shen, H., Ershoff, D., Afifi, A. A., and Bourque, L. B.: Exploring the causal relationship between exposure to the 1994 Northridge earthquake and pre- and post-earthquake preparedness activities, Earthq. Spectra, 22(3), 569-587, 2006.

Palm, R.: The Roepke lecture in economic geography. Catastrophic earthquake insurance: patterns of adoption, Econ. Geogr., 71(2), 119-131, 1995.

Palm, R.: Urban earthquake hazards. The impacts of culture on perceived risk and response in the USA and Japan, Appl. Geogr., 18(1), 35-46, 1998.

Palm, R. and Carroll, J.: Illusions of safety. Culture and earthquake hazard response in California and Japan, Westview Press, Boulder, CO, 1998.

Paradise, T. R.: Perception of earthquake risk in Agadir, Morocco: A case study from a Muslim community, Environ. Hazards, 6, 167-180, 2005.

Paradise, T. R.: Perceptions of seismic risk in a Muslim city, The Journal of North African Studies, 11(3), 243-262, 2006.

Paton, D.: Risk communication and natural hazard mitigation: how trust influences its effectiveness, International Journal of Global Environmental Issues (IJGENVI), 8(1-2), 2-16, 2008.

Paton, D., Bajek, R., Okada, N., and McIvor, D.: Predicting community earthquake preparedness: a cross-cultural comparison of Japan and New Zealand, Nat. Hazards, published online, doi:10.1007/s11069-010-9500-2, 5 March 2010.

Paton, D., Smith, L. M., and Johnston, D. M.: When good intentions turn bad: promoting natural hazard preparedness, Austr. J. Emerg. Manage., 20, 25-30, 2005

Perry, R. W. and Lindell, M. K.: Volcanic risk perception and adjustment in a multi-hazard environment, J. Volcanol. Geoth. Res., 172(3-4), 170-178, 2008.

Plapp, T. and Werner, U.: Understanding risk perception from natural hazards: examples from Germany, in: RISK21 - Coping with risks due to natural hazards in the 21 st century, edited by: Am- 
mann, W. J., Dannenmann, S., and Vulliet, L., Routledge, UK, 101-109, 2006.

Rozario, K.: The culture of calamity. Disaster and the making of modern America, The University of Chicago Press, Chicago, IL, USA, 2007.

Rozin, P., Lowery, L., Imada, S., and Haidt, J.: The CAD triad hypothesis: a mapping between three moral emotions (contempt, anger, disgust) and three moral codes (community, autonomy, divinity), J. Pers. Soc. Psychol., 76(4), 574-586, 1999.

Russell, L. A., Goltz, J. D., and Bourque, L. B.: Preparedness and hazard mitigation activities before and after two earthquakes, Environ. Behav., 27(6), 744-770, 1995.

Rüstemli, A. and Karanci, A. N.: Correlates of earthquake cognitions and preparedness behavior in a victimized population, J. Soc. Psychol., 139(1), 91-101, 1999.

Simpson-Housley, P. and Curtis, F. A.: Earthquake occurrence, experience and appraisal in Wellington, New Zealand, Prof. Geogr., 35(4), 462-467, 1983.

Slovic, P.: The perception of risk, Earthscan, London, UK, 2000.

Smith, L:. Encouraging protective behaviors in communities, in Disaster Resilience: an integrated approach, edited by: Paton, D. and Johnston, D., Charles C. Thomas Publisher Ltd., Springfield, IL, USA, 143-160, 2006.

Spittal, M. J., McClure, J., Siegert, R. J., and Walkey, F. H.: Optimistic bias in relation to preparedness for earthquakes, Australasian Journal of Disaster and Trauma Studies, vol. 20051, ISSN: 1174-4707, available at: http://www.massey.ac.nz/ $\sim$ trauma/issues/2005-1/spittal.htm, 2005.

Spittal, M. J., Walkey, F. H., McClure, J. L., Siegert, R. J., and Ballantyne, K. E.: The earthquake readiness scale: the development of a valid and reliable unifactorial measure, Nat. Hazards, 39, 15-29, 2006.
Spittal, M. J., McClure, J. L., Siegert, R. J., and Walkey, F. H.: Predictors of two types of earthquake preparation: survival activities and mitigation activities, Environ. Behav., 40(6), 798-817, 2008.

Stedman, R. C.: Toward a social psychology of place, Environ. Behav., 34(5), 561-581, 2002.

Steinberg, T.: Acts of God: the unnatural history of natural disaster in America, 2nd edn., Oxford University Press, New York, NY, USA, 2006.

Terry, D. J., Hogg, M. A., and White, K. M.: The theory of planned behaviour: self-identity, social identity and group norms, Brit. J. Soc. Psych., 38(3), 225-244, 1999.

Tierney, K. J., Lindell, M. K., and Perry, R. W.: Facing the Unexpected: Disaster Preparedness and Response in the United States, Joseph Henry Press, Washington, DC, USA, 2001.

Turner, R., Nigg, J., and Heller Paz, D.: Waiting for Disaster, University of California Press, Los Angeles, CA, USA, 1986.

Waugh, W. L.: Living with hazards, dealing with disasters: an introduction to emergency management, M. E. Sharpe, Armonk, NY, USA, 1999.

White, K. M., Smith, J. R., Terry, D. J., Greenslade, J. H., and McKimmie, B. M.: Social influence in the theory of planned behaviour: The role of descriptive, injunctive and in-group norms, Brit. J. Soc. Psych., 48(1), 135-158, 2009.

Whitney, D. J., Lindell, M. K., and Nguyen, L. H.: Earthquake beliefs and adoption of seismic hazard adjustments, Risk Anal., 24(1), 87-101, 2004.

Wisner, B., Blaikie, P., Cannon, T., and Davis, I.: At risk: natural hazards, people's vulnerability and disasters, Routledge, London, UK, 2004. 